\title{
The prevalence of stunting, overweight and obesity, and metabolic disease risk in rural South African children
}

Elizabeth W Kimani-Murage ${ }^{1 *}$, Kathleen Kahn ${ }^{1,2}$, John M Pettifor ${ }^{3}$, Stephen M Tollman ${ }^{1,2}$, David B Dunger ${ }^{4}$, Xavier F Gómez-Olivé', Shane A Norris ${ }^{3}$

\begin{abstract}
Background: Low- to middle-income countries are undergoing a health transition with non-communicable diseases contributing substantially to disease burden, despite persistence of undernutrition and infectious diseases. This study aimed to investigate the prevalence and patterns of stunting and overweight/obesity, and hence risk for metabolic disease, in a group of children and adolescents in rural South Africa.

Methods: A cross-sectional growth survey was conducted involving 3511 children and adolescents 1-20 years, selected through stratified random sampling from a previously enumerated population living in Agincourt subdistrict, Mpumalanga Province, South Africa. Anthropometric measurements including height, weight and waist circumference were taken using standard procedures. Tanner pubertal assessment was conducted among adolescents 9-20 years. Growth z-scores were generated using 2006 WHO standards for children up to five years and 1977 NCHS/WHO reference for older children. Overweight and obesity for those $<18$ years were determined using International Obesity Task Force BMI cut-offs, while adult cut-offs of BMI $\geq 25$ and $\geq 30 \mathrm{~kg} / \mathrm{m}^{2}$ for overweight and obesity respectively were used for those $\geq 18$ years. Waist circumference cut-offs of $\geq 94 \mathrm{~cm}$ for males and $\geq$ $80 \mathrm{~cm}$ for females and waist-to-height ratio of 0.5 for both sexes were used to determine metabolic disease risk in adolescents.
\end{abstract}

Results: About one in five children aged 1-4 years was stunted; one in three of those aged one year. Concurrently, the prevalence of combined overweight and obesity, almost non-existent in boys, was substantial among adolescent girls, increasing with age and reaching approximately $20-25 \%$ in late adolescence. Central obesity was prevalent among adolescent girls, increasing with sexual maturation and reaching a peak of 35\% at Tanner Stage 5, indicating increased risk for metabolic disease.

Conclusions: The study highlights that in transitional societies, early stunting and adolescent obesity may co-exist in the same socio-geographic population. It is likely that this profile relates to changes in nutrition and diet, but variation in factors such as infectious disease burden and physical activity patterns, as well as social influences, need to be investigated. As obesity and adult short stature are risk factors for metabolic syndrome and Type 2 diabetes, this combination of early stunting and adolescent obesity may be an explosive combination.

\footnotetext{
* Correspondence: lizmurage@gmail.com

${ }^{1}$ MRC/Wits Rural Public Health and Health Transitions Research Unit

(Agincourt), School of Public Health, Faculty of Health Sciences, University of the Witwatersrand, Johannesburg, South Africa
} 


\section{Background}

Understanding the prevalence and patterns of undernutrition, particularly stunting, the emergence of overweight/obesity in children and adolescents, and the concomitant risk for metabolic disease, is of criticial importance for public health policy. Undernutrition is a serious risk factor for ill health and contributes substantially to the burden of disease in low- to middle-income countries (LMICs) [1]. Increasing adverse ramifications of childhood undernutrition are recognised later in life, and include impaired cognitive development, poorer educational achievement and human capital formation [2], and greater risk for obesity [3].

A nutrition transition, often accompanied by changes in physical activity levels, is being experienced in LMICs. Nutrition transition refers to changes in diet composition from traditional diets that are primarily derived from plant-based food sources low in fat and high in fibre, to more "Western" diets that are high energy dense and low in fibre. This transition is driven by rapid economic transition, urbanisation, globalisation, technological and social changes $[4,5]$. Nutrition transition typically begins with urban populations and those in higher social economic strata [4], but is not limited to these populations. Increased intake of animal source foods and edible oils have been documented in less urbanised urban areas and more urbanised rural areas [6].

Nutrition transition is a major driving force behind the double burden of malnutrition, a phenomenon that has become important in LMICs where high levels of obesity have been documented despite persistence of undernutrition $[4,5]$. Obesity has led to the increased public health importance of diet-related non-communicable diseases, such as cardiovascular diseases and diabetes, in LMICs particularly in adults [1]. In line with the co-existence of undernutrition and obesity, a protracted-polarised model of epidemiologic transition has been documented in LMICs. In this non-classical model of epidemiologic transition, infectious diseases and undernutrition coexist with non-communicable diseases and persist over prolonged periods of time [7]. Therefore, both undernutritionrelated diseases, infectious diseases and obesity-related diseases contribute substantially to the burden of disease in these societies [1].

The problem of obesity and related metabolic disease risk is not only experienced among adults. Paediatric obesity has been documented in LMICs and is the driving force behind paediatric metabolic syndrome risk that has become a growing public health concern in LMICs [8]. Childhoood/adolescent obesity is associated with health problems for the child/adolescent including heightened risk of psychosocial morbidity, cardiovascular complications, and type 1 and type 2 diabetes [9]. Of further concern is the fact that obese children and adolescents are likely to be obese adults at increased risk of cardiovascular diseases and other morbidity, premature death, and impaired social, educational and economic productivity $[3,9]$.

The World Health Organization (WHO) recommends more research into the frequency of risk factors related to the metabolic syndrome and their levels in LMICs [1]. Given that the pace and nature of transitions vary across geo-cultural settings, local data and context is increasingly stressed. This is particularly so because such information is essential to local programming and policy. The aim of this study is to investigate the prevalence of stunting and overweight/obesity by age and sex and to estimate the risk for metabolic disease in a group of children and adolesents aged 1-20 years randomly selected from a health and socio-demographic surveillance site in Agincourt, rural South Africa. We postulate that in rural South Africa stunting remains a concern among children, and that the transition to an urban profile with regards to overweight and obesity is advanced.

\section{Methods}

\section{Study Setting and Population}

This study was conducted in rural northeast South Africa, in the Agincourt sub-district, Mpumalanga province, alongside the country's border with Mozambique. Agincourt is a semi-arid setting, situated in the former Gazankulu homeland. The study was nested within the Agincourt health and socio-demographic surveillance system (HDSS), of the University of the Witwatersrand. Established in 1992 and covering the entire Agincourt sub-district, the Agincourt HDSS follows some 70,000 people living in 11,700 households in 21 contiguous villages. The population comprises Tsonga-speaking people, some $30 \%$ of whom are of recent Mozambican origin having entered South Africa mainly as refugees in the early to mid-1980s following the civil war in Mozambique. The Mozambicans are also Tsonga-speaking, have widely intermarried with the host South African population, and exhibit similar cultures.

The area is characterised by high levels of poverty: Mpumalanga province has one of the highest poverty rates in South Africa, at 64\% [10]. There are high levels of unemployment: strict unemployment (excluding underemployment) is estimated at $29 \%$ for men and $46 \%$ for women [11]. Labour migration, mainly circular rural-urban migration, is widespread involving up to $60 \%$ of working age men and growing numbers of women [11]. Additionally, government support grants including the child support grant and pension for older people are an important source of income for many families. Being in a former homeland, the land is 
subdivided into plots too small to support subsistence farming. Housing material varies from traditional mud houses to brick houses. Piped water is available at community level, but there are frequent water shortages in most villages. Sanitation is poor, particularly in the former refugee settlements, with pit latrines of varying types from traditional pit latrines to ventilated improved pit latrines being the main method of excreta disposal in the area. Although the situation has improved in the last few years, roads are largely untarred and there is limited public transport with the main means of transport being privately owned taxis $[12,13]$. The area has benefited from the recent national electrification program. Access to education has improved in recent years: literacy levels have improved post-apartheid in the younger generation aged up to 29 years, but high illiteracy levels remain among the older generation, reaching levels of almost $80 \%$ for those aged 60 years and above [11]. Health care services are limited in the area: a network of five primary care clinics refers to a larger public health centre; the nearest district hospital is 25 kilometres away. The area is characterised by a high prevalence of HIV/AIDS, slightly over $30 \%$ among pregnant women visiting public antenatal health clinics in the province [14]. The study area, Agincourt HDSS and local demographics are described in detail elsewhere [12].

\section{Data collection}

The study was conducted between April and July 2007. The Agincourt HDSS, a longitudinal community surveillance system acted as the sampling frame for the study. It involves a systematic annual recording of vital demographic events including births, deaths and migrations occurring in all households in 21 contiguous villages in Agincourt sub-district. The baseline census was conducted in 1992 and data are updated annually. The study sample comprised children and adolescents aged 1-20 years selected from the entire population within this age spectrum in the Agincourt HDSS as at March 2007 ( $\mathrm{n}=34775 ; 50 \%$ boys and girls respectively). For analysis and documentation purposes, the ages were truncated to full years; thus, for example, 20 years refers to participants aged 20.0-20.9 years. Four thousand children and adolescents were targeted, comprising 100 males and 100 females for each year of age. We oversampled 10-15 children per age-sex group to counter possible non-participation. Thus a total of 4658 children were randomly selected from the Agincourt HDSS database. Only children who had lived in the study area at least $80 \%$ of the time since birth, or since 1992 when enrolment into the Agincourt HDSS began, were included. A random sample of children was drawn from each age-sex-village stratum in proportion to the population size of the village.
Written informed consent was obtained from the parent/caregiver of children aged 1-17 years and from adolescents 18-20 years themselves. Consent was obtained duringl household visits on weekdays, and participants were invited to data-collection camps over the weekends and holidays at centrally located schools within the study villages. Assent was also obtained from those aged 9-17 years prior to data collection. Ethical clearance was granted by the University of the Witwatersrand Committee for Research on Human Subjects, Medical (M070244).

Anthropometric measurements were carried out on all children and adolescents aged 1-20 years, and pubertal assessments were done on those 9-20 years old. Height was measured using a stadiometer (Holtain, UK) calibrated in millimeters. For all children aged less than 24 months, the determination of length was done using an inelastic tape measure in a recumbent position on a flat surface. Weight in kilograms (to one decimal point) was determined using a mechanical bathroom scale (Hanson, UK). Waist circumference was measured in milimetres using an inelastic tape measure at the natural waist (midway between the tenth rib and the illiac crest) with the participant in a standing position. All measurements were carried out according to standard procedures [15].

Pubertal assessment in children 9 years and older was obtained using the Tanner 5-point pubertal self-rating scale which has been validated for Black South Africans [16]. This self-administered questionnaire was conducted for males and females separately, with the assistance of same-sex interviewers who explained how to complete the assessment prior to the participants completing the questionnaire. The five Tanner stages reflect physical development based on external primary and secondary sex characteristics: pubic hair in girls and boys, breast development in girls and genitalia in boys [17]. Genital development in boys and breast development in girls were used to define the stages in this study.

\section{Data quality}

A team of 12 fieldworkers was carefully trained by experts in anthropometric measurements. To minimise fieldworker variation, each fieldworker specialised in a specific measurement and collected the data on all study participants. Coefficient of variation for anthropometric measurements was determined before and towards end of the study period; on average, the coefficient of variation towards the end of the study ranged between $<1 \%$ and $3 \%$ for the different measurements.

\section{Data analysis}

Weight-for-age z-scores (WAZ), height-for-age z-scores (HAZ) and weight-for-height z-scores (WHZ) for children up to 60 completed months were generated using 
the 2006 World Health Organization (WHO) growth standards with the WHO Anthro 2005 program, Beta Version [18]. Z-scores for those aged 5-17 years were determined using the 1977 National Center for Health Statistics (NCHS)/WHO reference. For the WHO standards, weight-for-length standards range from 45 to $110 \mathrm{~cm}$ (for children aged younger than 24 months) while weight-for-height standards (for children 2460 months) range from 65 to $120 \mathrm{~cm}$ for both sexes. For the NCHS/WHO reference, weight-for-length reference ranges from 49 to $103 \mathrm{~cm}$ and weight-for-height 55 to $145 \mathrm{~cm}$ for boys (up to 11 years approximately); while for girls, weight-for-length reference ranges from 49 to $101 \mathrm{~cm}$ and weight-for-height 55 to $137 \mathrm{~cm}$ (up to 9 years approximately). Thus, for the purpose of comparisons by sex, WHZ scores were calculated for all children up to 9 years.

Overweight and obesity in children 2-17 years were determined using the absolute age and sex specific cutoffs for body mass index (BMI) recommended by the International Obesity Taskforce (IOTF) [19]. These are defined to pass through BMI of 25 and $30 \mathrm{~kg} / \mathrm{m}^{2}$ at 18 years for overweight and obesity respectively. For adolescents 18-20 years, adult cut-off points of BMI $\geq$ 25 and $\geq 30 \mathrm{~kg} / \mathrm{m}^{2}$ for overweight and obesity respectively, were used [20].

Studies have shown that waist circumference is a better predictor of child and adolescent risk of metabolic disease than BMI, or improves the ability of BMI in predicting this [21]. We used waist circumference alone and in combination with height in estimating the metabolic disease risk [22]. Waist-to-height ratio (WHtR) was generated by dividing waist circumference by height. The percentage of those at risk of metabolic disease was estimated among adolescents who had attained at least Tanner stage 3 as it was assumed that these had attained approximately adult height. This was done using cut-offs of waist circumference of $\geq 94 \mathrm{~cm}$ for males and $\geq 80 \mathrm{~cm}$ for females [23], and waist-to-height ratio of 0.5 for both sexes [22].

Data analysis was done using Stata version 10.0 (StataCorp LP, College Station, Texas, USA). Patterns of the prevalence of stunting (HAZ <-2), underweight (WAZ $<-2$ ), wasting (WHZ <-2), overweight and obesity by age and sex were determined. The Student t-test was used to test the differences between means across age-sex groups, and the chi-square test for differences in proportions by age and sex. A p-value of $<0.0500$ was considered statistically significant.

\section{Results}

Nearly $80 \%$ (3511 participants) of the randomly selected sample participated in the study. Non-participation was due to failure to present for measurements after giving consent (9\%), refusal to consent (1\%), absence due to being in boarding school (8\%), out-migration from study area (3\%), and being away for other reasons (3\%). From the 3511 participants, 22 were excluded from the analysis: pregnant adolescents $(n=9)$, severely mentally and physically disabled children $(n=11)$, one case with spurious date of birth, and one case with erroneous measurements. A total of 3489 children were included in the analysis: $1724(49.4 \%)$ males and 1765 (50.6) females aged between 1-20 years. Distribution of participants included in the analysis by sex and year of age is shown in Table 1. Further, the distribution of adolescents 9-20 years by Tanner pubertal stages is shown in Table 2. Most boys were in stages 1 and 2 while most girls were in stages $3-5$. Only $5 \%$ of boys had reached stage 5.

\section{Prevalence of stunting, underweight and wasting by age and sex}

Figure 1 shows the prevalence of stunting, underweight and wasting for boys and girls at each age, with the level of significance by sex indicated by an asterisk on the bars. The prevalence of stunting fell from $32 \%$ at 1 year to plateau at approximately 3-6\% from 5 years, before rising to $14-15 \%$ in boys during adolescence between years 14 and 15 . Stunting was significantly

Table 1 Distribution of study participants aged 1-20 years $(n=3489)$, by age and sex, Agincourt sub-district, South Africa, 2007

\begin{tabular}{|c|c|c|c|c|}
\hline \multirow[t]{2}{*}{ Age (mean) } & \multicolumn{2}{|c|}{ Boys } & \multicolumn{2}{|c|}{ Girls } \\
\hline & $\mathbf{N}$ & $\%$ & $\mathbf{N}$ & $\%$ \\
\hline $1(1.6)$ & 70 & 4.1 & 67 & 3.8 \\
\hline $2(2.5)$ & 83 & 4.8 & 77 & 4.4 \\
\hline $3(3.5)$ & 103 & 6.0 & 91 & 5.2 \\
\hline $4(4.5)$ & 82 & 4.8 & 98 & 5.6 \\
\hline $5(5.5)$ & 87 & 5.1 & 86 & 4.9 \\
\hline $6(6.5)$ & 104 & 6.0 & 94 & 5.3 \\
\hline $7(7.5)$ & 91 & 5.3 & 110 & 6.2 \\
\hline $8(8.6)$ & 111 & 6.4 & 97 & 5.5 \\
\hline $9(9.5)$ & 90 & 5.2 & 100 & 5.7 \\
\hline $10(10.5)$ & 98 & 5.7 & 101 & 5.7 \\
\hline $11(11.5)$ & 105 & 6.1 & 97 & 55 \\
\hline $12(12.5)$ & 96 & 5.6 & 89 & 5.0 \\
\hline 13(13.5) & 94 & 5.5 & 97 & 5.5 \\
\hline $14(14.5)$ & 78 & 4.5 & 89 & 5.0 \\
\hline $15(15.5)$ & 82 & 4.8 & 99 & 5.6 \\
\hline $16(16.5)$ & 74 & 4.3 & 94 & 5.3 \\
\hline $17(17.5)$ & 69 & 4.0 & 67 & 3.8 \\
\hline 18(18.5) & 80 & 4.6 & 63 & 3.6 \\
\hline 19(19.5) & 70 & 4.0 & 67 & 3.8 \\
\hline \multirow[t]{2}{*}{$20(20.6)$} & 57 & 3.3 & 82 & 4.7 \\
\hline & 1724 & & 1765 & \\
\hline
\end{tabular}


Table 2 Distribution of adolescents aged 9-20 years by sex and pubertal stage $(n=2006)$, Agincourt sub-district, South Africa, 2007

\begin{tabular}{llllll}
\hline & & \multicolumn{2}{c}{ Boys } & Girls & $\begin{array}{l}\text { Significant difference by sex } \\
\text { (P-value) }\end{array}$ \\
\cline { 1 - 4 } Stage & Mean age (SD) & N (\%) & Mean age & N (\%) & \\
\hline 1 & $11.3(1.5)$ & $254(26)$ & $10.5(1.1)$ & $156(15)$ & $\mathrm{P}<0.0001$ \\
2 & $13.3(2.4)$ & $296(30)$ & $12.0(1.7)$ & $186(18)$ & $\mathrm{P}<0.0001$ \\
3 & $16.4(2.3)$ & $188(19)$ & $14.6(2.4)$ & $243(24)$ & $\mathrm{P}<0.0001$ \\
4 & $18.1(1.9)$ & $193(20)$ & $16.9(2.3)$ & $306(30)$ & $\mathrm{P}<0.0001$ \\
5 & $18.5(1.8)$ & $45(5)$ & $18.3(2.0)$ & $139(14)$ & $\mathrm{P}=0.3954$ \\
\hline
\end{tabular}

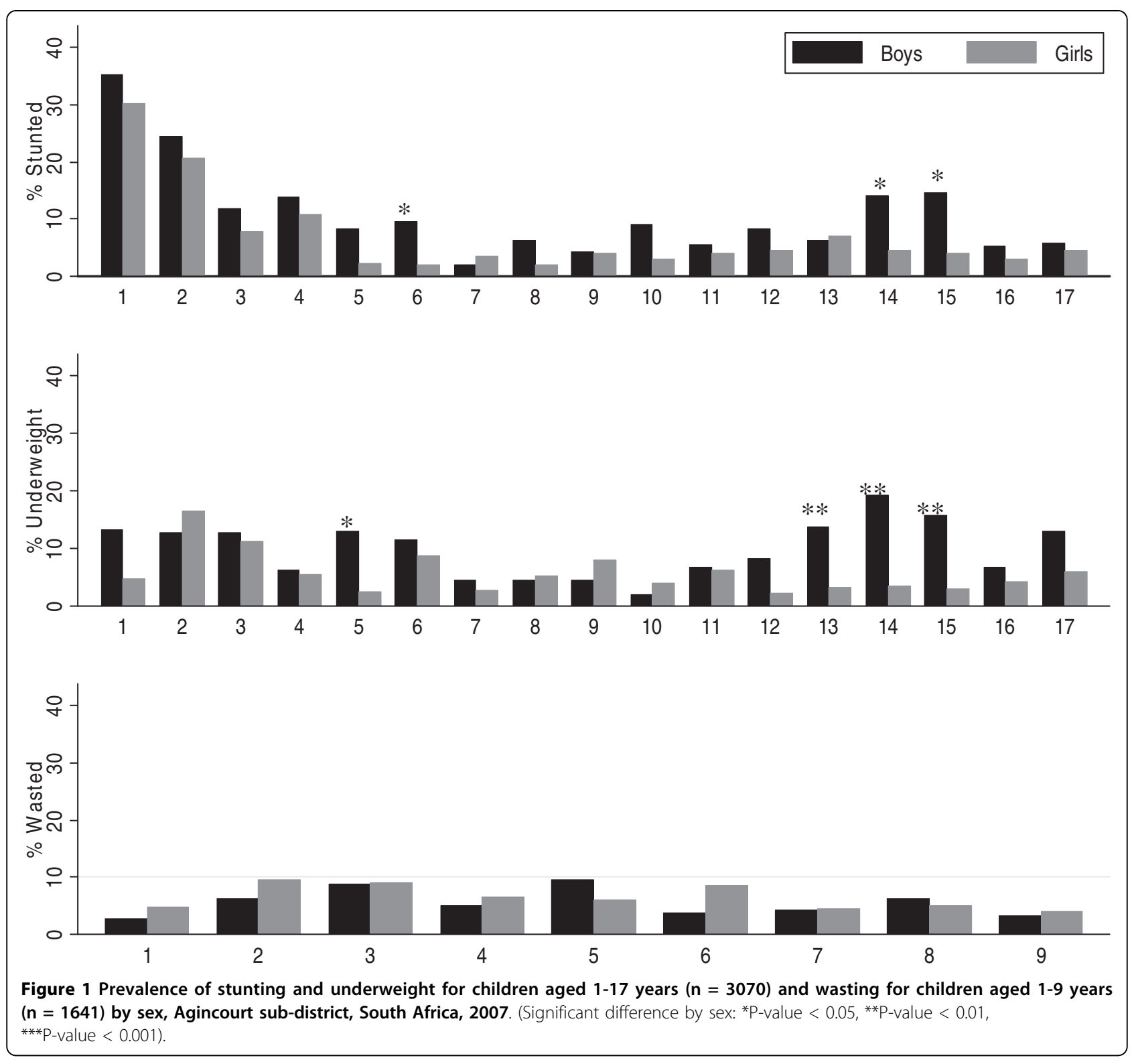


Table 3 Comparison of Prevalence of malnutrition in current study with national studies in South Africa

\begin{tabular}{|c|c|c|c|c|c|c|c|c|c|c|c|c|c|c|c|c|c|}
\hline \multirow[t]{2}{*}{ Study } & \multirow[t]{2}{*}{ Population (n) } & \multirow[t]{2}{*}{ Reference } & \multicolumn{3}{|c|}{ Stunted \% } & \multicolumn{3}{|c|}{ Underweight \% } & \multicolumn{3}{|c|}{ Wasted \% } & \multicolumn{3}{|c|}{ Overweight \% } & \multicolumn{3}{|c|}{ Obese \% } \\
\hline & & & U & $\mathbf{R}$ & $\mathbf{N}$ & $U$ & $\mathbf{R}$ & $\mathbf{N}$ & $U$ & $\mathbf{R}$ & $\mathbf{N}$ & U & $\mathbf{R}$ & $\mathbf{N}$ & $U$ & $\mathbf{R}$ & $\mathrm{N}$ \\
\hline SAVACG (1994) & 6-71 mo (11430) & WHO/NCHS & 16 & 27 & 23 & 7 & 11 & 9 & 2 & 3 & 3 & & & & & & \\
\hline NFCS (1999) & $1-9$ y $(2894)$ & WHO/NCHS IOTF & 17 & 27 & 22 & 8 & 13 & 10 & 2 & 5 & 4 & 13 & 12 & 12 & 6 & 4 & 5 \\
\hline YRBS (2002) & Approx. 13-19 y (9224) & WHO/NCHS IOTF & - & - & 11 & - & - & 9 & - & - & 4 & - & - & 17 & - & - & 4 \\
\hline DHS (2003) & $<5$ y $(1159)$ & WHO/NCHS & 27 & 28 & 27 & 12 & 11 & 12 & 6 & 5 & 5 & - & - & - & - & - & - \\
\hline NFCS (2005) & $1-9$ y (2469) & WHO/CDC IOTF & 16 & 20 & 18 & 9 & 9 & 9 & 5 & 4 & 4 & 10 & 10 & 10 & 4 & 4 & 4 \\
\hline \multirow[t]{5}{*}{ Agincourt (2007) } & $1-20$ y (3489) & WHO WHO/NCHS IOTF & - & 8 & - & - & 7 & - & - & 6 & - & - & 6 & - & - & 2 & - \\
\hline & $1-4$ y $(671)$ & & - & 18 & - & - & 10 & - & - & 7 & - & & 7 & - & - & 1 & - \\
\hline & $5-9$ y $(970)$ & & - & 5 & - & - & 6 & - & - & 6 & - & & 4 & - & - & 1 & - \\
\hline & 10-14 y (944) & & - & 7 & - & - & 7 & - & - & - & - & & 6 & - & - & 2 & - \\
\hline & $15-20$ y (904) & & - & 6 & - & - & 8 & - & - & - & - & & 8 & - & - & 4 & - \\
\hline
\end{tabular}

$\mathrm{U}=$ Urban; $\mathrm{R}=$ Rural; $\mathrm{N}=$ National

Sources:

SAVACG (1994): The South African Vitamin A Consultative Group, 1995 [29]

NFCS (1999): Labadarios et al., 2005 [28]

YRBS (2002): Reddy et al., 2008 [41]

DHS (2003): Department of Health, 2003 [27]

NFCS 2005: Department of Health, 2007 [26]

Agincourt (2007): Current study

greater in boys than girls at 6,14 and 15 years $(\mathrm{p}<$ 0.0500 respectively). Stunting was the most prevalent form of undernutrition for younger children aged 1-4 years at $18 \%$ (Table 3 ).

The prevalence of underweight in younger children ranged between 6 and 14\% for children 1-6 years, was lower for children between ages 7 and 12 years, and peaked at $19 \%$ in boys aged 14 years. The prevalence of underweight was significantly higher in boys than in girls at ages 5, 13, 14 and $15(\mathrm{p}<0.0500)$.

The prevalence of wasting was uncommon at age 1 year but increased to approximately $4-9 \%$ between 2-9 years. There was no difference in wasting by sex.

\section{Prevalence of stunting, underweight and wasting by Tanner pubertal staging and sex}

Figure 2 shows the prevalence of stunting, underweight and wasting in children at Tanner stages $1-5$, with the level of significance by sex indicated by an asterisk on the bars. There was no significant difference in stunting by sex at the various Tanner stages. Stunting was highest at Tanner stage 1 for both girls and boys at an average of $9 \%$, and reduced with increasing stage to about $1 \%$ at Tanner stage 5 . Boys at Tanner stage 2 and 3 were significantly more underweight than girls at the same stage; $11 \%$ vs. $4 \%(\mathrm{p}=0.0080)$ and $10 \%$ vs. $2 \%$ $(\mathrm{p}=0.0010)$ respectively.

\section{Prevalence of overweight and obesity by age and sex}

Figure 3 shows the prevalence of overweight and obesity by age and sex with the level of significance by sex indicated with an asterisk on the bars. The prevalence of overweight and obesity was moderate in early childhood and low in late childhood, and remained so in older boys. However, the prevalence rose progressively in girls aged 10 years and older. Consequently, girls had significantly higher prevalence of combined overweight and obesity $(\mathrm{p}<0.0500)$ than boys at ages 10 and $12-20$ years; at age 15 years, significance was borderline ( $\mathrm{p}=$ $0.0500)$. From age 14 years, overweight and obesity averaged some $18 \%$ in females compared to $4 \%$ in males, reaching approximately $20-25 \%$ in late adolescence in girls.

Co-existence of stunting and combined overweight and obesity in the same child was common in children aged less than five years (18\%), but was uncommon in older children aged 5-9 years (5\%) and adolescents aged $10-20$ years $(3 \%)$.

\section{Prevalence of overweight and obesity by Tanner stages}

Figure 4 depicts the relationship between the prevalence of overweight and obesity with Tanner pubertal stage in girls and boys. Combined overweight and obesity in girls was low in the earlier stages of puberty, but increased markedly during the later stages (from $7 \%$ to $35 \%)$; while in boys the prevalence remained low throughout the stages. The prevalence of combined overweight and obesity was significantly different between males and females at Tanner stages 3, 4 and 5 ( $\mathrm{p}<0.0010$ respectively).

\section{Risk for metabolic disease}

Risk for metabolic disease, defined by central obesity using waist circumference and WHtR cut-offs $[22,23]$ 


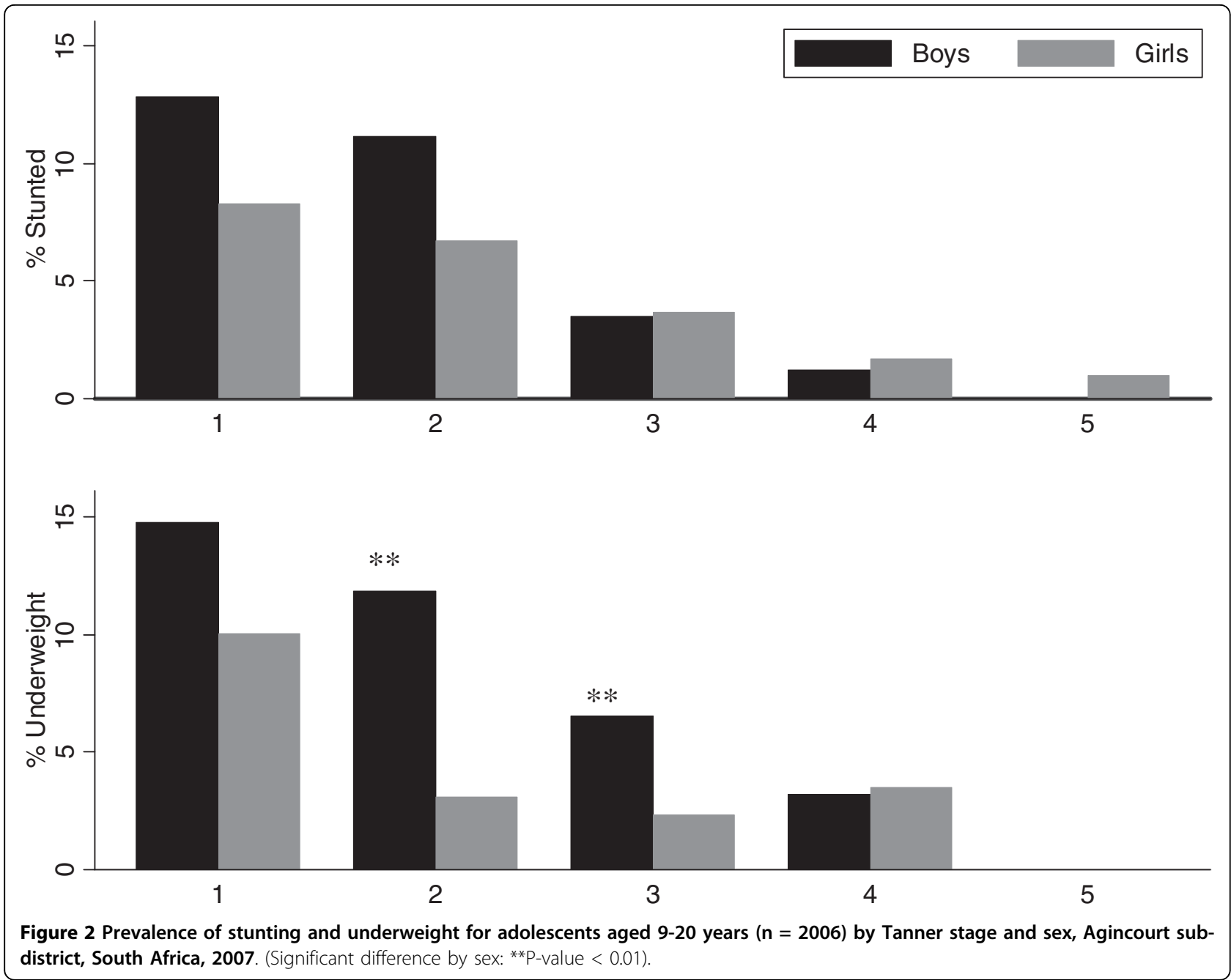

among adolescents at Tanner stages $3-5$, is presented by sex and pubertal stage in Figure 5. Using the waist circumference cut-offs, about $10 \%$ of adolescents were potentially at risk of metabolic disease; significantly higher proportion of girls (16\%) than boys (1\%) ( $\mathrm{p}<$ $0.0001)$. Similarly, using the waist-to-height cut-offs, $10 \%$ of adolescents were potentially at risk with significantly higher proportion of girls (15\%) than boys (3\%) $(\mathrm{p}<0.0001)$. The prevalence of risk using the different cut-offs increased with increasing pubertal stage in girls: $5 \%$ in girls at Tanner stage 3 using the waist circumference cut-offs, increasing to $35 \%$ at Tanner stage 5 . There were significant differences by sex across all the Tanner stages using the waist circumference and WHtR cut-offs ( $\mathrm{p}<0.05$ at all stages respectively). Surprisingly, no boys were at risk of metabolic disease in Tanner stage 5 using the two cut-offs. However, there were fewer boys $(\mathrm{n}=45)$ who had attained this pubertal stage compared to girls $(\mathrm{n}=139)$.

\section{Discussion and Conclusions}

This study presents evidence of a double-pronged problem of malnutrition; undernutrition and overweight/obesity in children and adolescents living in a rural South African community. This phenomenon is evident in societies undergoing nutrition transition in LMICs $[4,5]$. This study also documents noteworthy levels of overweight and obesity and central obesity among adolescent girls, indicating an elevated risk for metabolic disease. These findings are relevant to the heightened public health interest in paediatric metabolic syndrome in LMICs [8]. Both undernutrition and overnutrition traverse the life course and are important both at the individual and national level $[2,9,24]$. Further, both paediatric obesity and adult short stature are risk factors for the metabolic syndrome and Type 2 diabetes in adulthood $[9,25]$. Hence the combination of early stunting and adolescent obesity raises critical concerns. The study calls for urgent evidence-based policy development and 


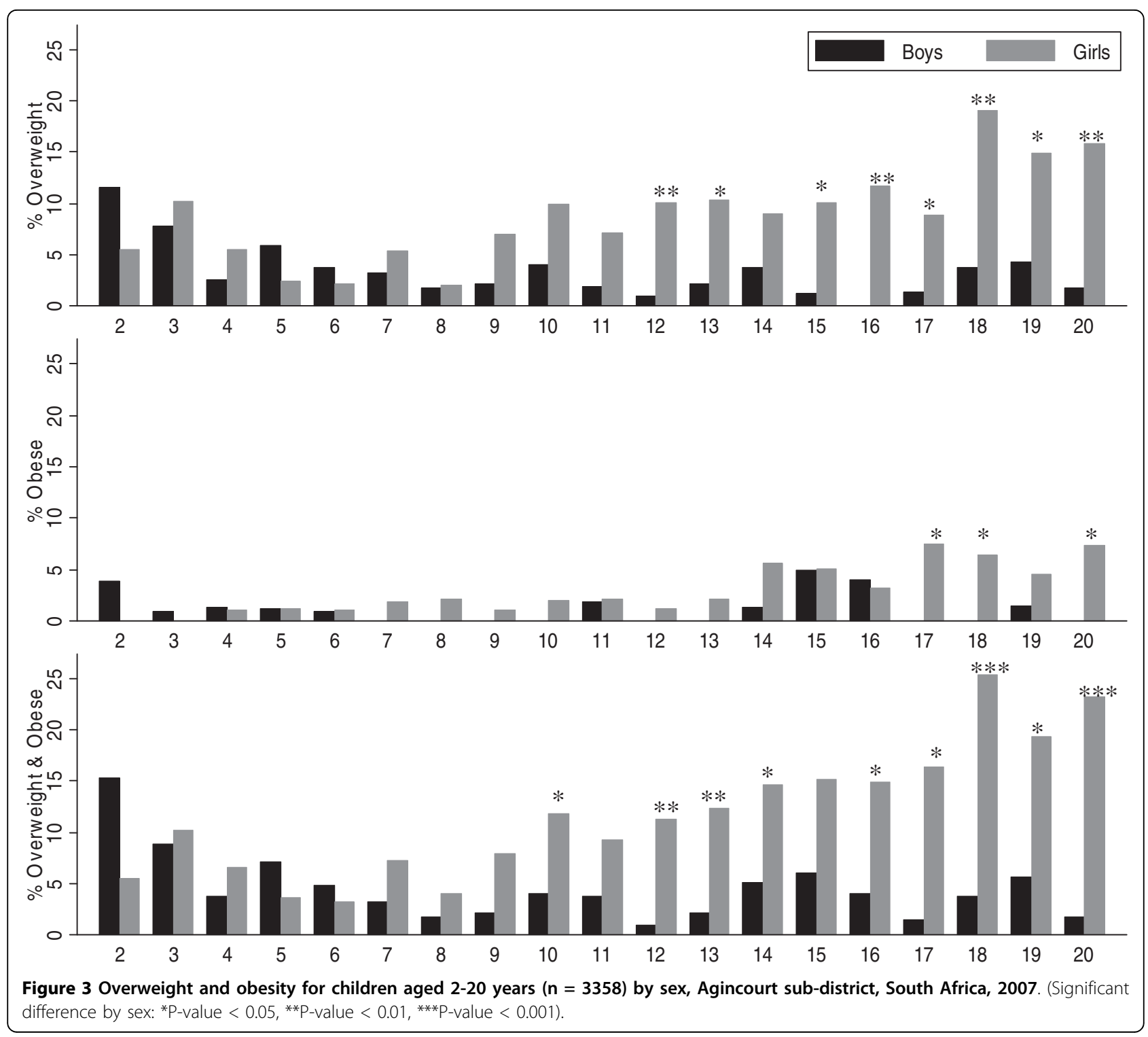

interventions to address the dual problem of malnutrition in rural South Africa.

The levels of undernutrition in young children in this rural population correspond with earlier findings in South Africa [26-29] (see Table 3). They indicate the persistence of undernutrition in rural communities despite recent efforts to address household food insecurity, in part through the introduction of child support grants and old age pensions. Despite South Africa being a middle-income country, food insecurity remains a problem with some $35 \%$ of households considered food insecure [30]. The Agincourt area is typical of former apartheid homeland areas with a limited food production base. Located in geographically inhospitable areas, land is sub-divided into plots that are generally too small to support subsistence agriculture. This results in people having to rely substantially on purchased food which - in an area where people have low purchasing power - may result in food insecurity and consequent undernutrition. The poor nutritional outcomes shown in our study participants may not only be associated with the quantity of food but also the quality. Food variety and dietary diversity, which are associated with nutritional status of South African children, are limited in poor communities in South Africa [31]. The potential role of HIV/AIDS in the persistence of undernutrition in our study community cannot be underestimated. The high prevalence of HIV among women of child bearing age [14] indicates that many households are HIV affected. HIV/AIDS has an extensive effect on food security as it undermines the ability of households to provide for their basic needs [32]. Research in the study 


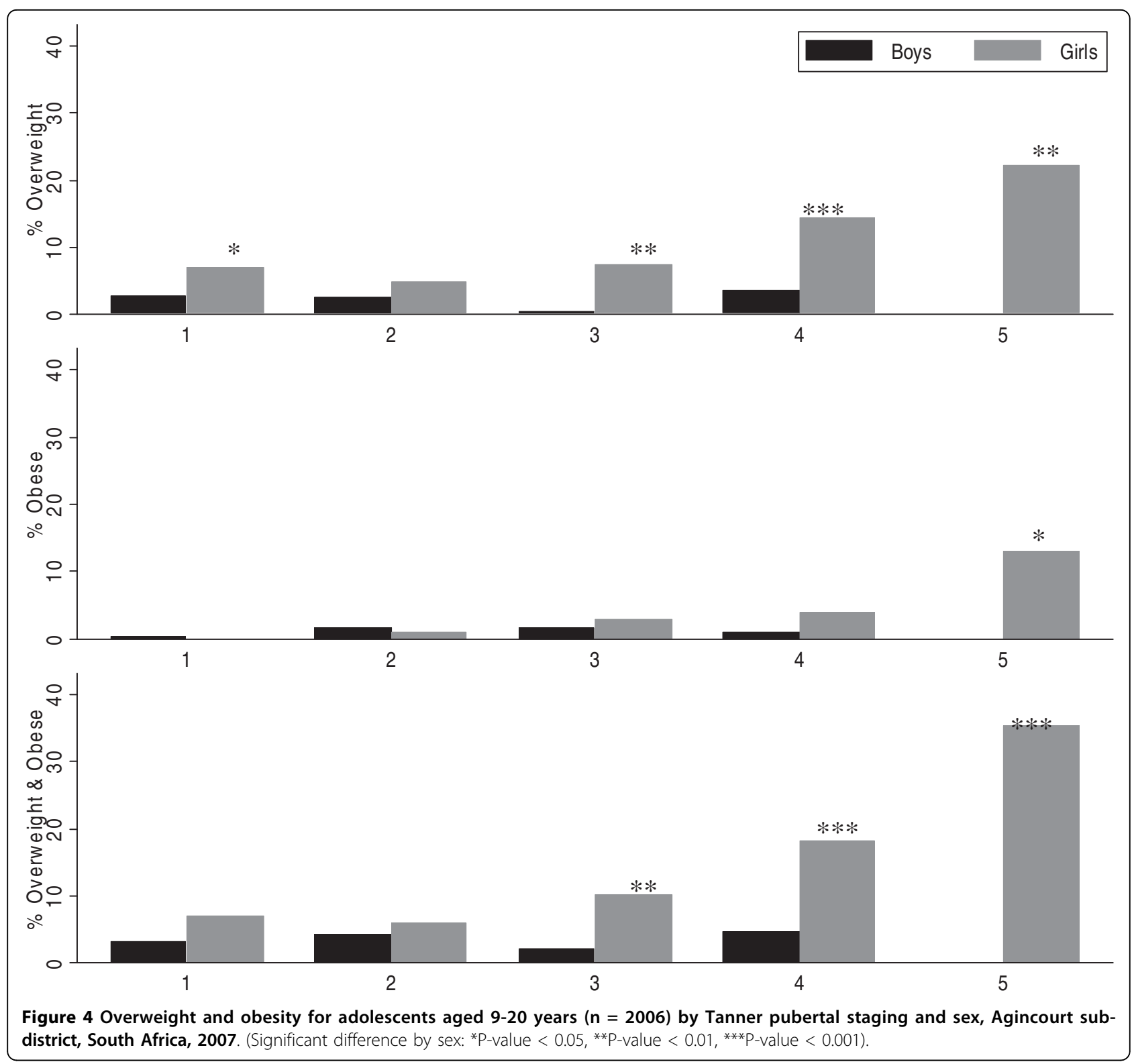

area shows that adult mortality, particularly that of a male wage-earner, affects household food security and that people often fall back on wild foods as a coping strategy [33]. Death of a mother has been associated with a fourfold increase in the odds of child undernutrition in the study area [34].

The results show higher prevalence of undernutrition amongst adolescent boys compared to girls. This confirms findings on adolescents in other South African studies [35] and on younger children elsewhere in subSaharan Africa [36]. The differential prevalence of undernutrition by sex in our study is likely to be due to delay in the pubertal growth spurt in boys compared to the reference group. This occurs where undernutrition is prevalent [37]. Other studies in South Africa have documented delayed pubertal development for children in rural areas compared to their urban counterparts [38]. Other factors may contribute to these differences because even after stratifying by pubertal stage, boys at Tanner stages 2 and 3 still showed significantly higher levels of underweight compared to girls in the same stage. Evidence amongst younger children indicates that disproportionate male undernutrition occurs in households with low socio-economic status; in better off households, the sex difference disappears [39]. Further investigations into the sex differences of malnutrition during adolescence in our study may be required. 


\section{Waist circumference}
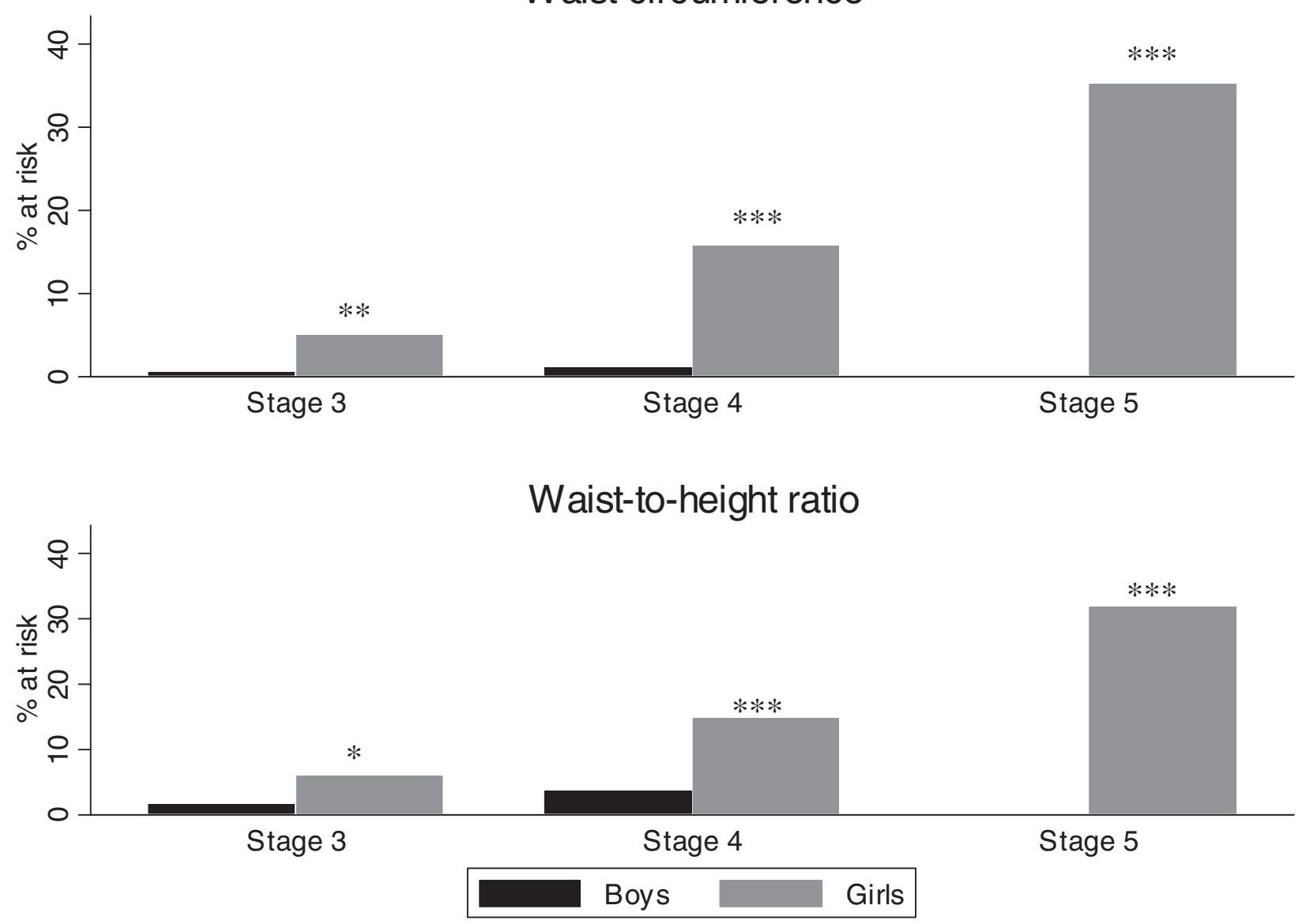

Figure 5 Metabolic disease risk using waist circumference and waist-to height ratio cut-offs for adolescents in tanner stages 3-5 ( $\mathrm{n}=$ 1114) by Tanner stage and sex, Agincourt sub-district, South Africa, 2007. (Significant difference by sex: ${ }^{* P}$-value $<0.05$, ${ }^{* *}$-value $<0.01$, ***P-value $<0.001)$.

In addition to the substantial prevalence of undernutrition documented in this study are noteworthy levels of overweight and obesity among adolescents, particularly girls. The levels of overweight/obesity are comparable to those documented in other rural areas in South Africa [40]. These levels are, however, lower than those recorded in various national surveys (Table 3 ) $[26,28,41]$, indicating that there may be areas with very high levels. The South African Youth Risk Behaviour Survey 2002 documented a prevalence of combined overweight and obesity of $21 \%$ among adolescents in grades 8-11 (approx 13-19 years) nationally; 7\% in boys and $25 \%$ in girls [41]. Our study documented a prevalence of about $10 \%$ in this age group; $4 \%$ in boys and $16 \%$ in girls.

As with overweight and obesity, prevalence of central obesity was substantial particularly amongst adolescent girls. Central obesity, measured using waist circumference alone or in combination with other measures, is an integral risk indicator for metabolic syndrome [23]. The risk in this study increased with sexual maturation, indicating higher risk as the adolescents transition to adulthood. The finding of a substantial level of central obesity is important as childhoood/adolescent metabolic syndrome risk is increasingly becoming a concern in LMICs [8]. Childhoood/adolescent overweight/obesity is associated with many health problems for the child/adolescent including heightened risk of psychosocial morbidity, asthma, orthopaedic difficulties, cardiovascular complications, and type 1 and type 2 diabetes [9]. Further, overweight/obese children and adolescents are likely to be obese adults at increased risk of cardiovascular and other morbidity, premature death, and impaired social, educational and economic productivity [3,9]. Risk components for the metabolic syndrome have been tracked from childhood to adulthood in several studies [42]. This emphasises the importance of identifying these risk factors and addressing the problem early 
during childhood to prevent transfer of these risks to adulthood.

The higher prevalence of obesity among adolescent girls compared to boys in this study is in keeping with many studies in other LMICs [43] and in South Africa in particular [35]. Several factors may explain these sex differences. Biologically, energy needs differ for boys and girls and also in relation to rate of growth. Further, timing of sexual maturation differs by sex [44]. Behavioural factors are also important in explaining the sex differences: boys are generally more physically active compared to girls especially during adolescence $[45,46]$. Concerns about body image, particularly among adolescent girls, may lead to problematic eating behaviours such as irregular meal patterns which may result in increased weight gain [47]. Differential problematic eating behaviours by sex have been reported among South African youth [48].

The phenomenon of a double burden of malnutrition documented in this study is becoming increasingly important in LMICs undergoing nutrition transition $[4,5]$. Several factors shed light on why this phenomenon is occuring in rural South Africa. Literature on early developmental programming describes how nutritional deprivation during the foetal period and early childhood leads to adaptations that may result in obesity during later life [3]. This may partly explain the co-occurrence of stunting in early childhood with overweight and obesity during adolescence in our study. Further, change of food cultures and lifestyle may also play a major role. Studies on urbanisation in South Africa have reported decreased intake of staple foods including maize meal, and increased intake of energy-dense foods including added fats and oils and animal-derived foods [49]. Similar findings have been documented in other LMICs undergoing nutrition transition [4]. Over-reliance on energy-dense processed foods, purchased due to insufficient local food production, may be a key factor in the development of adolescent overweight and obesity in the study area. Extensive labour migration to larger towns [11] facilitates the transfer and introduction of urban practices to rural settings with consequent change in diet and lifestyle. Women's participation in the labour force, increasingly reported in the study area, may also impact on food supply and diet [11].

Physical inactivity and sedentary lifestyles are associated with childhood/adolescent overweight and obesity [50]. National electrification in South Africa in the last few years, with consequent increase in televisions at home, may have resulted in decreased physical activity. Studies in South Africa have reported decreased physical activity among adolescents $[45,46]$. Increased television viewing by children/adolescents may also be associated with increased consumption of unhealthy foods seen in television advertisements [51]. Length of television viewing by children/adolescents has been associated with higher consumption of fast foods and other high energy dense food and lower intake of fruits and vegetables [52]. Contribution of these factors to the patterns of obesity we have observed need further investigations.

Despite the important findings in our study, a few limitations should be noted. This study did not collect data on food intake and physical activity patterns which would help explain the findings. However, further work is underway to determine factors associated with nutritional status in the study area, including dietary patterns and physical activity levels. Owing to the Agincourt HDSS sampling frame used, there were no infants in the study sample. This may have implications for findings, particularly with regards to undernutrition. There was higher non-participation among older adolescents. This may indicate over-representation of the study sample by younger children and may have implications for the overall findings. Despite these limitations, it is important to point out the strength of the sampling procedure employed. The sampling was purely random, using an existing sampling frame, and representative of the study area as the study sample was drawn from the various villages in proportion to the population size of the villages. The findings provide useful picture of patterns of nutritional status among children and adolescents in rural South Africa. They also raise important questions that could be followed up in future studies.

Our findings have implications at individual, community and national levels that traverse the life course. The importance of both paediatric undernutrition and overweight/obesity cannot be overemphasised $[1,2,8]$. The overweight/obesity prevalence we have observed in this study, particularly in adolescent girls, may partly contribute to the high levels of overweight/obesity reported in South African adults, particularly in women [27]. The level of central obesity in adolescent girls indicates risk of later metabolic disease. This is of major public health importance as South Africa is undergoing an epidemiologic transition with chronic non-communicable diseases associated with obesity contributing markedly to the burden of disease in this community and other parts of South Africa- despite the burden due to infectious diseases and undernutrition [53-55]. At national level, undernutrition may ultimately affect the gross domestic product through lowered economic productivity - malnourished children are more likely to have poor educational outcomes leading over time to lower incomes, higher fertility, and suboptimal care for their children, thereby contributing to the intergenerational transfer of poverty $[2,24]$.

In conclusion, child growth and nutrition in rural South Africa is clearly shifting along the rural-urban 
continuum and is tending towards an urban-like profile. Persisting prevalence of undernutrition, particularly stunting, at an early age suggests inadequate interventions to address food insecurity and undernutrition. It also indicates possible need to intervene during the perinatal period. The prevalence of substantial levels of overweight and obesity in the same community presents a multifaceted policy and programme challenge. It is likely that this profile relates to changes in nutrition and dietary patterns, but variation in other factors such as infectious disease burden and physical activity including exercise, as well as social influences, need to be investigated. We therefore recommend a scaling up of research and programme evaluation in order to inform policy on effective intervention strategies that can address the double-pronged problem of malnutrition.

\section{Abbreviations}

HDSS: Health and socio-demographic surveillance system; AIDS: Acquired immune deficiency syndrome; BMI: Body mass index; CDC: Centers for Disease Control and Prevention; Cm: Centimetre(s); DALYs: Disability-adjusted life years; DoH: Department of Health; HAZ: Height-for-age z-scores; HIV: Human immunodeficiency virus; Kg: Kilogram(s); IOTF: International Obesity Taskforce; LMICs: Low- to middle-income countries; M: Metre(s); MDGs: Millennium development goals; NFCS: National food consumption survey; NCHS: National Center for Health Statistics; SAVACG: The South African Vitamin A Consultative Group; UK: United Kingdom; USA: United States of America; USD: United States dollar; WAZ: Weight-for-age z-scores; WHO: World Health Organization; WHtR: Weight-for-height ratio; WHZ: Weight-forheight z-scores; YRBS: Youth risk behaviour survey.
\end{abstract}

\section{Acknowledgements}

We acknowledge funding from the National Research Foundation (NRF) and the Medical Research Council (MRC), South Africa. The Agincourt health and socio-demographic surveillance system is funded by the Wellcome Trust, UK (069683/Z/02/Z) and is a member of the INDEPTH Network. Elizabeth Kimani-Murage has a PhD fellowship funded by the Flora and William Hewlett Foundation, USA, while Dr. Shane Norris holds a Wellcome Trust Research Fellowship. We acknowledge logistical support from the MRCNits Rural Public Health and Health Transitions Research Unit (Agincourt) during data collection and from the African Population and Health Research Center, Kenya during preparation of this manuscript. We acknowledge Mark Collinson and Kerstin Klipstein-Grobusch for their technical contributions during design of the study. We acknowledge the data collection team and the LinC office team at the MRC/Wits Rural Public Health and Health Transitions Research Unit (Agincourt) specifically Rhian Twine, Geoffrey Tibane and Audrey Khosa for their role in community mobilization. We also acknowledge the training team and the data entry team from the Birth To Twenty program, University of the Witwatersrand, South Africa funded by the Wellcome Trust, UK (077210/Z/05/Z). This paper was presented and received useful comments at the Public Health Association of South Africa (PHASA) conference, 2008, the INDEPTH Network annual general meeting, 2008, and the University of the Witwatersrand inter-faculty post-graduate symposium, 2008. It was also presented and reviewed in a seminar at the School of Public Health, University of the Witwatersrand, South Africa.

\section{Author details}

'MRC/Wits Rural Public Health and Health Transitions Research Unit (Agincourt), School of Public Health, Faculty of Health Sciences, University of the Witwatersrand, Johannesburg, South Africa. ${ }^{2}$ Umeå Centre for Global Health Research, Department of Public Health and Clinical Medicine, Umeå University, Umeå, Sweden. ${ }^{3}$ MRC Mineral Metabolism Research Unit, Department of Paediatrics, Faculty of Health Sciences, University of the Witwatersrand, Johannesburg, South Africa. ${ }^{4}$ Department of Paediatrics, University of Cambridge, Cambridge, UK.

\section{Authors' contributions}

EWK-M: Design of the study, project management, training and supervising fieldworkers, data management and analysis, writing of the manuscript. Read and approved the final manuscript. KK: Design of the study, overall project co-ordination, reviewing of the manuscript. Read and approved the final manuscript. JMP: Design of the study, review of the manuscript. Read and approved the final manuscript. SMT: Design of the study, review of the manuscript. Read and approved the final manuscript. DD: Design of the study, review of the manuscript. Read and approved the final manuscript. FXG: Design of the study, training of field workers, implementation and supervision of field work, review of the manuscript. Read and approved the final manuscript. SAN: Design of the study, overall project management, reviewing of the manuscript. Read and approved the final manuscript.

\section{Competing interests}

The authors declare that they have no competing interests.

Received: 1 December 2009 Accepted: 25 March 2010 Published: 25 March 2010

\section{References}

1. World Health Organization: World Health Report 2002: Reducing Risks, Promoting Healthy Life WHO, Geneva 2002.

2. Victora CG, Adair L, Fall C, Hallal PC, Martorell R, Richter L, Sachdev HS, Maternal, Child Undernutrition Study G: Maternal and child undernutrition: consequences for adult health and human capital. Lancet 2008, 371(9609):340-357.

3. Lanigan J, Singhal A: Early nutrition and long-term health: a practical approach. Proc Nutr Soc 2009, 1-8.

4. Food and Agriculture Organization (FAO) of the United Nations: The double burden of malnutrition Case studies from six developing countries FAO food and nutrition paper 84 . Rome 2006.

5. Popkin B: The Nutrition Transition in the Developing World. Dev Policy Rev 2003, 21(5-6):581-597.

6. Mendez M, Du SF, Popkin B: Urbanization, income and the nutrition transition in China: a case study. FAO. Globalization of food systems in developing countries: impact on food security and nutrition FAO Food and Nutrition Paper No. 83. Rome 2004, 169-194.

7. Frenk J, Bobadilla J, Stern C, Frejka T, Lozano R: Elements for a theory of the health transition. Health and Social Change in International Perspective Boston: Harvard University PressChen LC, Kleinman A, Ware NC 1994, 25-49.

8. Kelishadi R: Childhood overweight, obesity, and the metabolic syndrome in developing countries. Epidemiol Rev 2007, 29:62-76.

9. Reilly JJ, Methven E, McDowell ZC, Hacking B, Alexander D, Stewart L, Kelnar CJ: Health consequences of obesity. Arch Dis Child 2003, 88(9):748-752.

10. Gelb S: Inequality in South Africa: Nature, causes and responses. Johannesburg: The EDGE Institute 2003.

11. Collinson MA: Striving against Adversity: the Dynamics of Migration, Health and Poverty in Rural South Africa. PhD Thesis Umeå University, Department of Public Health and Clinical Medicine 2009.

12. Kahn K, Tollman SM, Collinson MA, Clark SJ, Twine R, Clark BD, Shabangu M, Gomez-Olive FX, Mokoena O, Garenne ML: Research into health, population and social transitions in rural South Africa: data and methods of the Agincourt Health and Demographic Surveillance System. Scand J Public Health 2007, 35(Suppl 69):8-20.

13. Hargreaves J: Village typology: The Agincourt field site. Descriptive results and preliminary discussion. Working Papers Johannesburg: Agincourt Health and Population Unit, University of the Witwatersrand 2000.

14. Department of Health: National HIV and syphilis antenatal seroprevalence survey in South Africa: 2007. Pretoria 2008.

15. Lohman TG, Roche AF, Martorell R: Anthropometric standardization reference manual Champaign, IL: Human Kinetics Books 1991.

16. Norris SA, Richter LM: Usefulness and Reliability of Tanner Pubertal SelfRating to Urban Black Adolescents in South Africa. J Res Adolescence 2005, 15(4):609-624.

17. Tanner JM: Growth at Adolescence Oxford: Blackwell 1962.

18. World Health Organization: WHO Anthro 2005, Beta version Feb 17th, 2006: Software for assessing growth and development of the world's children. Volume Beta version Feb 17th, 2006 WHO, Geneva 2006 
19. Cole TJ, Bellizzi MC, Flegal KM, Dietz WH: Establishing a standard definition for child overweight and obesity worldwide: international survey. BMJ (Clinical research ed) 2000, 320(7244):1240-1243.

20. World Health Organization: Obesity: preventing and managing the global epidemic. Report of a WHO consultation. World Health Organ Tech Rep Ser 2000, 894:i-xii, 1-253.

21. Genovesi S, Antolini L, Giussani M, Pieruzzi F, Galbiati S, Valsecchi MG, Brambilla P, Stella A: Usefulness of waist circumference for the identification of childhood hypertension. J Hypertens 2008, 26(8):1563-1570

22. Ashwell M: Obesity risk: importance of the waist-to-height ratio. Nurs Stand 2009, 23(41):49-54, quiz 55.

23. Alberti KG, Zimmet $P$, Shaw J: Metabolic syndrome-a new world-wide definition. A Consensus Statement from the International Diabetes Federation. Diabet Med 2006, 23(5):469-480.

24. World Bank: Repositioning Nutrition as Central to Development The World Bank, Washington, DC 2006.

25. Bosy-Westphal A, Plachta-Danielzik S, Dorhofer RP, Muller MJ: Short stature and obesity: positive association in adults but inverse association in children and adolescents. Br J Nutr 2009, 102(3):453-461.

26. Department of Health: National Food Consumption Survey-Fortification Baseline (NFCS-FB):South Africa, 2005. Stellenbosch 2007.

27. Department of Health, Medical Research Council, ORC Macro: South Africa Demographic and Health Survey 2003. Pretoria 2007.

28. Labadarios D, Steyn NP, Maunder E, MacIntryre U, Gericke G, Swart R, Huskisson J, Dannhauser A, Vorster HH, Nesmvuni AE, et al: The National Food Consumption Survey (NFCS): South Africa, 1999. Public Health Nutr 2005, 8(5):533-543.

29. The South African Vitamin A Consultative Group: Children aged 6 to 71 months in South Africa, 1994: Their anthropometric, vitamin A, iron and immunisation coverage status. Johannesburg 1995.

30. Health Sciences Research Council (HSRC) South Africa: Food Security in South Africa: Key Policy Issues for the Medium Term. Integrated Rural and Regional Development, Southern African Regional Poverty Network. Pretoria 2004.

31. Steyn NP, Nel JH, Nantel G, Kennedy G, Labadarios D: Food variety and dietary diversity scores in children: are they good indicators of dietary adequacy?. Public Health Nutr 2006, 9(5):644-650.

32. de Waal A, Whiteside A: New variant famine: AIDS and food crisis in southern Africa. Lancet 2003, 362(9391):1234-1237.

33. Hunter LM, Twine W, Patterson L: "Locusts are now our beef": adult mortality and household dietary use of local environmental resources in rural South Africa. Scand J Public Health 2007, 35(Suppl 69):165-174.

34. Madhavan S, Townsend N: The social context of children's nutritional status in rural South Africa. Scand J Public Health 2007, 35(Suppl 69):107-117

35. Jinabhai CC, Reddy P, Taylor M, Monyeki D, Kamabaran N, Omardien R, Sullivan KR: Sex differences in under and over nutrition among schoolgoing Black teenagers in South Africa: an uneven nutrition trajectory. Trop Med \& Intl Health: TM \& IH 2007, 12(8):944-952.

36. Wamani H, Astrom AN, Peterson S, Tumwine JK, Tylleskar T: Boys are more stunted than girls in sub-Saharan Africa: a meta-analysis of 16 demographic and health surveys. BMC Pediatr 2007, 7:17.

37. Sedlmeyer IL, Palmert MR: Delayed puberty: analysis of a large case series from an academic center. Clin Endocrinol Metab 2002, 87(4):1613-1620.

38. Cameron N, Grieve CA, Kruger A, Leschner KF: Secondary sexual development in rural and urban South African black children. Ann Hum Biol 1993, 20(6):583-593.

39. Wamani H, Tylleskar T, Astrom AN, Tumwine JK, Peterson S: Mothers' education but not fathers' education, household assets or land ownership is the best predictor of child health inequalities in rural Uganda. Int J Equity Health 2004, 3(1):9.

40. Monyeki KD, Monyeki MA, Brits SJ, Kemper HC, Makgae PJ: Development and tracking of body mass index from preschool age into adolescence in rural South African children: Ellisras Longitudinal Growth and Health Study. J Health Popul Nutr 2008, 26(4):405-417.

41. Reddy S, Resnicow K, James S, Kambaran N, Omardien R, Mbewu A: Underweight, overweight and obesity among South African adolescents: results of the 2002 National Youth Risk Behaviour Survey. Public Health Nutr 2008, 1-5.
42. Eisenmann JC, Welk GJ, Wickel EE, Blair SN: Stability of variables associated with the metabolic syndrome from adolescence to adulthood: the Aerobics Center Longitudinal Study. Am J Hum Biol 2004, 16(6):690-696.

43. Neutzling MB, Taddei JA, Rodrigues EM, Sigulem DM: Overweight and obesity in Brazilian adolescents. Int J Obes Relat Metab Disord 2000, 24(7):869-874.

44. Wisniewski AB, Chernausek SD: Gender in childhood obesity: family environment, hormones, and genes. Gend Med 2009, 6(Suppl 1):76-85.

45. Kruger R, Kruger HS, Macintyre UE: The determinants of overweight and obesity among 10- to 15-year-old schoolchildren in the North West Province, South Africa - the THUSA BANA (Transition and Health during Urbanisation of South Africans; BANA, children) study. Public Health Nutr 2006, 9(3):351-358.

46. Reddy SP, Panday S, Swart D, Jinabhai CC, Amosun SL, James S, Monyeki KD, Stevens G, Morejele N, Kambaran NS, et al: Umthenthe Uhlaba Usamila - The South African Youth Risk Behaviour Survey 2002. South African Medical Research Council, Cape Town 2003.

47. Neumark-Sztainer D, Paxton SJ, Hannan PJ, Haines J, Story M: Does body satisfaction matter? Five-year longitudinal associations between body satisfaction and health behaviors in adolescent females and males. J Adolesc Health 2006, 39(2):244-251.

48. le Grange D, Telch CF, Tibbs J: Eating attitudes and behaviors in 1,435 South African Caucasian and non-Caucasian college students. Am J Psychiatry 1998, 155(2):250-254.

49. Vorster $\mathrm{HH}$, Venter CS, Wissing MP, Margetts BM: The nutrition and health transition in the North West Province of South Africa: a review of the THUSA (Transition and Health during Urbanisation of South Africans) study. Public Health Nutr 2005, 8(5):480-490.

50. Lajous M, Chavarro J, Peterson KE, Hernandez-Prado B, Cruz-Valdez A, Hernandez-Avila M, Lazcano-Ponce E: Screen time and adiposity in adolescents in Mexico. Public Health Nutr 2009, 1-8.

51. Morgan M, Fairchild R, Phillips A, Stewart K, Hunter L: A content analysis of children's television advertising: focus on food and oral health. Public Health Nutr 2009, 12(6):748-755.

52. Taveras EM, Sandora TJ, Shih MC, Ross-Degnan D, Goldmann DA, Gillman MW: The association of television and video viewing with fast food intake by preschool-age children. Obesity (Silver Spring) 2006, 14(11):2034-2041.

53. Tollman SM, Kahn K, Sartorius B, Collinson MA, Clark SJ, Garenne ML: Implications of mortality transition for primary health care in rural South Africa: a population-based surveillance study. Lancet 2008, 372(9642):893-901

54. Kahn K, Garenne ML, Collinson MA, Tollman SM: Mortality trends in a new South Africa: Hard to make a fresh start. Scand J Public Health 2007, 35(Suppl 69):26-34.

55. Kruger HS, Venter CS, Vorster HH: Obesity in African women in the North West Province, South Africa is associated with an increased risk of noncommunicable diseases: the THUSA (Transition and Health during Urbanisation of South Africans) study. Br J Nutr 2001, 86(6):733-740.

\section{Pre-publication history}

The pre-publication history for this paper can be accessed here: http://www. biomedcentral.com/1471-2458/10/158/prepub

\section{doi:10.1186/1471-2458-10-158}

Cite this article as: Kimani-Murage et al:: The prevalence of stunting, overweight and obesity, and metabolic disease risk in rural South African children. BMC Public Health 2010 10:158. 